PNL-SA-25595

\title{
THEORY AND NUMERICAL APPLICATION OF SUBSURFACE FLOW AND TRANSPORT FOR TRANSIENT FREEZING CONDITIONS
}

M. D. White

April 1995

Prepared for

the U.S. Department of Energy

under Contract DE-AC06-76RLO 1830

Pacific Northwest Laboratory

Richland, Washington 99352

Presented at the

Fifteenth Annual "Hydrology Days" Conference

April 3-7, 1995

Ft. Collins, Colorado

\section{DISCLAIMER}

This report was prepared as an account of work sponsored by an agency of the United States Government. Neither the United States Government nor any agency thereof, nor any of their employees, makes any warranty, express or implied, or assumes any legal liability or responsibility for the accuracy, completeness, or usefulness of any information, apparatus, product, or process disclosed, or represents that its use would not infringe privately owned rights. Reference herein to any specific commercial product, process, or service by trade name, trademark, manufacturer, or otherwise does not necessarily constitute or imply its endorsement, recommendation, or favoring by the United States Government or any agency thereof. The views and opinions of authors expressed herein do not necessarily state or reflect those of the United States Government or any agency thereof. 


\section{DISCLAIMER}

Portions of this document may be illegible in electronic image products. Images are produced from the best available original document. 


\title{
Theory and Numerical Application of Subsurface Flow and Transport for Transient Freezing Conditions
}

\author{
M.D. White 1
}

\begin{abstract}
Protective barriers are being investigated for the containment of radioactive waste within subsurface environments. Predicting the effectiveness of cryogenic barriers and near-surface barriers in temperate or arctic climates requires capabilities for numerically modeling subsurface flow and transport for freezing soil conditions. A predictive numerical model is developed herein to simulate the flow and transport of radioactive solutes for three-phase (water-iceair) systems under freezing conditions. This physically based model simulates the simultaneous flow of water, air, heat, and radioactive solutes through variably saturated and variably frozen geologic media. Expressions for ice (frozen water) and liquid water saturations as functions of temperature, interfacial pressure differences, and osmotic potential are developed from nonhysteretic versions of the Brooks and Corey and van Genuchten functions for soil moisture retention. Aqueous relative permeability functions for variably saturated and variably frozen geologic media are developed from the Mualem and Burdine theories for predicting relative permeability of unsaturated soil. Soil deformations, caused by freezing and melting transitions, are neglected. Algorithms developed for predicting ice and liquid water saturations and aqueous-phase permeabilities were incorporated into the finite-difference based numerical simulator STOMP (Subsurface Transport Over Multiple Phases). Application of the theory is demonstrated by the solution of heat and mass transport in a horizontal cylinder of partially saturated porous media with differentially cooled ends, with the colder end held below the liquid water freezing point. This problem represents an essential capability for modeling cryogenic barriers in variably saturated geologic media.
\end{abstract}

\section{INTRODUCTION}

Frozen soil barriers, referred to as cryogenic barriers, have been proposed for temporarily containing plumes of radioactive and/or organic contamination within the subsurface environment. Field-scale experiments of frozen soil barriers require significant investments in refrigeration and monitoring equipment and time for planning and executing. Numerical modeling of cryogenic barrier systems with proven, physically based simulators can cut the requirements for field-scale testing, by providing mechanisms for appropriately scaling laboratory experiments to field applications. Critical components of a physically based simulator for freezing conditions are the constitutive relations for predicting liquid water and ice saturations and aqueous relative permeabilities as a function of temperature, interfacial pressure differences, and osmotic potential.

1 Earth and Environmental Sciences Center, Pacific Northwest Laboratory, P.O. Box 999, Richland,WA 99352. email: md_white@pnl.gov. 
Theories on the mechanisms of fluid-heat flow and transport in partially frozen soil have been proposed by many investigators. Selected-studies have been summarized by Kay and Perfect [1988]. Harlan [1973] numerically computed coupled heat-fluid transport in partially frozen soil by assuming that the saturation and relative permeability properties of frozen and partially frozen soil were directly analogous to those for partially saturated unfrozen soil at similar energy states. Jame and Norum [1980] compared numerical and laboratoryscale experimental results involving coupled heat and mass transport under freezing conditions. Unfrozen water saturations were computed from an empirical expression, which was derived from experimental measurements. Soil hydraulic conductivities were estimated from values reported for similar soils. Engelmark and Svensson [1993] compared numerical solutions against the experimental data of Jame and Norum [1980]. As with the previous work, expressions for unfrozen water content as a function of temperature were empirical. Guymon and Luthin [1974] outlined a procedure for estimating volumetric water and ice contents and hydraulic conductivities as a function of temperature by using the Clausius-Clapeyron equation to relate changes in temperature with pore water pressure. Fuchs et al. [1978] expanded on the work of Guymon and Luthin [1974] by substituting the soil water potential, as proposed by Cary and Maryland [1972], for the matric potential to estimate the relation between soil temperature and liquid water content at subfreezing temperatures. Panday and Corapcioglu [1994] described a conceptual model for predicting equilibrium saturations for a water-oil-air system in frozen soils, which included ice saturations. In this conceptual model, phase saturations were related to scaled two-phase capillary pressures.

The primary objective of this paper is to propose a general formulation for computing liquid water and ice (frozen water) saturations and liquid water relative permeabilities as a function of interfacial pressure differences, solute concentration, and temperature for variably saturated, freezing conditions. This formulation will build on the theories of previous researchers [ Guymon and Luthin 1974; Fuchs et al. 1978; Cary and Maryland 1972; Panday and Corapcioglu 1994] and use modified forms of the conventional expressions for soil moisture retention and phase relative permeability [van Genuchten 1980; Brooks and Corey 1964; Burdine 1953; Mualem 1976]. A secondary objective of this paper is to demonstrate the proposed formulations in a numerical simulation of a transient heat and mass transfer problem with freezing conditions. The investigations in this paper do not consider the processes of ice-lens formation or frost heaving.

\section{SATURATION-PRESSURE RELATIONS}

Functional relations between phase saturations and interphase capillary pressures are required to numerically model fluid flow in variably saturated and variably frozen geologic media. In the following derivations two critical assumptions are made (1) ice formation occurs in the largest water filled pore spaces and (2) a thin film of water always surrounds the ice. This latter assumption implies that ice is completely occluded by the aqueous phase and that no direct air-ice interfaces occur. Characterization of three-phase systems requires two saturation-capillary pressure relations. Because retention curves for all phase pairs can be related to the retention curve of any two-phase interface in geologic media, the form of the retention function for both saturation-capillary pressure relations will be identical [Leverett and Lewis 1941]. For water-ice-air systems under equilibrium conditions two interfaces 
occur, gas-aqueous and ice-aqueous; where the aqueous phase is considered the wetting phase for both fluid pairs. Following thexamples of Parker and Lenhard [1987] for determining multiphase retention functions for water-oil-air systems by extending the relations for two-phase systems, two relations are formed. The first function relates the apparent aqueous saturation to the scaled gas-aqueous capillary pressure, and the second function relates the fraction of unfrozen water to the ice-aqueous capillary pressure [Panday and Corapcioglu 1994]. The apparent aqueous saturation is defined as the ratio of "free" aqueous saturation to the normalized "free" pore volume as

$$
\overline{\bar{s}}_{\ell}=\frac{s_{\ell}-\bar{s}_{m}}{1-s_{i}-\bar{s}_{m}}, \text { where } \bar{s}_{m}=s_{m} s_{u f}
$$

where $\overline{\bar{s}}$ is the apparent saturation, $\bar{s}$ is the effective saturation, $s$ is the actual saturation, the subscript $i$ indicates ice, the subscript $\ell$ indicates aqueous phase, the subscript $m$ indicates irreducible, and the subscript $u f$ indicates unfrozen fraction. Because residual water is free to freeze, within the limit of the ice-water interface penetrating the residual water pore spaces, the effective irreducible saturation is defined to vary with ice saturation as shown in Equation (1). The effective aqueous saturation represents the mobile liquid water. Its definition follows the conventional form, except that the irreducible saturation is replaced by the effective irreducible saturation as

$$
\bar{s}_{\ell}=\frac{s_{\ell}-\bar{s}_{m}}{1-\bar{s}_{m}}
$$

The unfrozen water fraction is defined as the ratio of actual aqueous saturation to the sum of the actual aqueous and ice saturations as

$$
s_{u f}=\frac{s_{\ell}}{s_{\ell}+s_{i}}
$$

The ice pressure can be related to the aqueous pressure, osmotic potential, and temperature by assuming thermodynamic equilibrium conditions and neglecting soil deformations and their interactions. An expression of thermodynamic equilibrium between ice and water in geologic media has been derived by Loch [1977] as

$P_{i}=\rho_{i}\left[\frac{P_{\ell}-\pi}{\rho_{\ell}}-h_{i w}^{o} \ln \left(\frac{T}{T^{o}}\right)\right]$, where $\pi=C_{\ell} R T$

where $P$ is the phase pressure $(\mathrm{Pa}), \rho$ is the phase density $\left(\mathrm{kg} / \mathrm{m}^{3}\right)$, $\pi$ is the osmotic pressure (Pa), $h_{i w}$ is the heat of fusion for water-ice $(\mathrm{J} / \mathrm{kg})$, $T$ is the temperature (K),C is the solute concentration $\left(\mathrm{kgmol} / \mathrm{m}^{3}\right), R$ is the universal gas constant, $(8314.3 \mathrm{~J} / \mathrm{kgmol} \mathrm{K})$, and the superscript $o$ indicates reference conditions.

As noted above, it is assumed that a single saturation-capillary pressure function can be used for arbitrary phase pairs in porous media by scaling the capillary pressures to eliminate the fluid dependent effects. Miller [1980] has 
investigated using the air-ice capillary pressure to determine the equilibrium configurations of water, ice, and air. However, with the assumption that no air-ice interfaces occur, equilibrium configurations for freezing conditions will be determined from scaled air-water and ice-water interfacial pressure differences. With this approach the generic expression for apparent aqueous saturation as a function of the gas-aqueous capillary pressure appears as

$$
\overline{\bar{s}}_{\ell}\left(\beta_{g \ell} h_{g \ell}\right)=s^{*}\left(h^{*}\right) \text {, where } h_{g \ell}=\left[\frac{\left(P_{g}-P_{\ell}\right)}{\rho_{\ell} g}\right]
$$

where, $\beta_{i j}$ is the scaling factor for fluid pair $i j, h_{i j}$ is the capillary head (m) for fluid pair $i j$, and $g$ is the acceleration of gravity $\left(\mathrm{m} / \mathrm{s}^{2}\right)$. Similarly, the generic expression for unfrozen water fraction as a function of the ice-aqueous capillary pressure appears as

$$
s_{u f}\left(\beta_{i \ell} h_{i \ell}\right)=s^{*}\left(h^{*}\right), \text { where } h_{i \ell}=\left[\frac{\left(P_{i}-P_{\ell}\right)}{\rho_{\ell} g}\right]
$$

Scaling factors can be computed from the ratio of interfacial tensions [Lenhard 1994] as

$$
\beta_{i j}=\frac{\sigma^{*}}{\sigma_{i j}}, \therefore \beta_{g \ell}=\frac{\sigma_{g \ell}}{\sigma_{g \ell}}=1 \text { and } \beta_{g \ell}=\frac{\sigma_{g \ell}}{\sigma_{i \ell}}
$$

where $\sigma_{i j}$ is the interfacial surface tension $(\mathrm{N} / \mathrm{m})$ for fluid pair $i j$ and the gasaqueous interfacial tension is chosen as the reference fluid system.

Various empirical forms have been published for the soil moisture retention function, relating phase saturation and capillary pressure, which may be adopted to parameterize the generic functions shown in Equations (5) and (6). The soil moisture retention theories of van Genuchten [1980] and Brooks and Corey [1964] will be applied here. Using the theory of van Genuchten the retention expressions for apparent aqueous saturation and unfrozen water fraction appear as

$$
\begin{aligned}
& \overline{\bar{s}}_{\ell}=\left[\begin{array}{ll}
1+(\alpha & h_{g \ell}
\end{array}\right]^{n} \text { for } h_{g \ell}>0 \text { and } \overline{\bar{s}}_{\ell}=1 \text { for } h_{g \ell} \leq 0 \\
& \left.s_{u f}=\left[\begin{array}{lll}
1+(\alpha & \beta_{i \ell} & h_{i \ell}
\end{array}\right]^{n}\right]^{-m} \text { for } h_{i \ell}>0 \text { and } s_{u f}=1 \text { for } h_{i \ell} \leq 0
\end{aligned}
$$

where $\alpha(1 / \mathrm{m}), m$, and $n$ are van Genuchten curve fitting parameters. Similarly, using the retention relation developed by Brooks and Corey [1964] the apparent aqueous saturation and unfrozen water fraction appear as 


$$
\begin{aligned}
& \overline{\bar{s}}_{\ell}=\left(\frac{h_{g \ell}}{\psi}\right)^{-\lambda} \text { for } h_{g \ell} \geq \psi \text { and } \overline{\bar{s}}_{\ell}=1 \text { for } h_{g \ell}<\bar{\psi} \\
& \overline{\bar{s}}_{\ell}=\left(\frac{\beta_{g \ell} h_{g \ell}}{\psi}\right)^{-\lambda} \text { for } \beta_{g \ell} h_{g \ell} \geq \psi \text { and } \overline{\bar{s}}_{\ell}=1 \text { for } \beta_{g \ell} h_{g \ell}<\psi
\end{aligned}
$$

where $\lambda$ and $\psi(\mathrm{m})$ are Brooks and Corey curve fitting parameters. Ice saturation as a function of temperature and solute concentration for the van Genuchten function is shown graphically in Figure 1, for a constant total water saturation (i.e., $s_{t}=s_{\ell}+s_{i}$ ) of 0.9 and zero-ice solute concentrations of 0.0 , 1.0 , and $2.0 \mathrm{~mol} / \mathrm{L}$. In these curves, solute concentrations in the aqueous phase increased with increasing ice saturation, because of the exclusion of solute within the ice phase (i.e. no solute absorption).

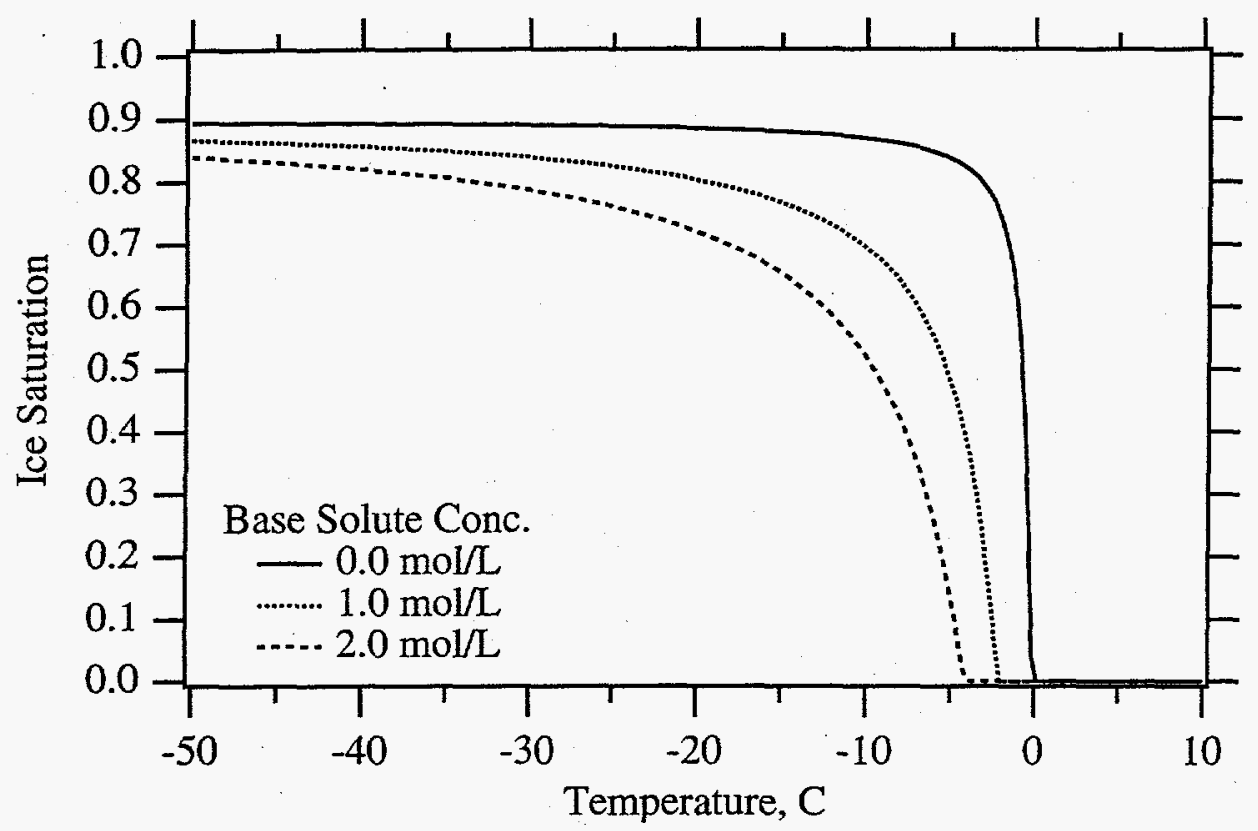

Figure 1. Ice Saturations for the van Genuchten Function $\alpha=0.01 \mathrm{~m}^{-1}, n=2.0, m=1-1 / n, s_{\ell}+s_{i}=0.9, s_{m}=0.1$

\section{RELATIVE PERMEABILITY-SATURATION RELATIONS}

Modeling fluid flow and solute transport in variably saturated, frozen geologic media systems requires knowledge of the functional relations between phase saturations and fluid permeabilities. Relative permeability functions for waterice-air systems are developed that relate aqueous-phase relative permeabilities to effective aqueous saturations. In the following derivations it is assumed that liquid water completely occludes ice and that no direct ice-gas interfaces occur. The presence of occluded ice will result in the obstruction of aqueous-phase flow and simultaneously displace aqueous fluid into larger pore spaces. To account for these opposing effects the models of Mualem [1976] and Burdine 
[1953] for aqueous relative permeability in two-phase water-air systems are modified, respectively, as

$$
\begin{aligned}
& k_{r_{\ell}}=\left(\bar{s}_{\ell}\right)^{1 / 2}\left[\frac{\int_{0}^{\bar{s}_{\ell}} \frac{d \zeta}{h(\zeta)}-\int_{\bar{s}_{\ell}}^{\bar{s}_{\ell}} \frac{d \zeta}{h(\zeta)}}{\int_{0}^{1} \frac{d \zeta}{h(\zeta)}}\right]^{2} \\
& k_{r \ell}=\left(\bar{s}_{\ell}\right)^{2}\left[\frac{\int_{0}^{\bar{s}_{\ell}} \frac{d \zeta}{h^{2}(\zeta)}-\int_{\bar{s}_{\ell}}^{\bar{s}_{\ell}} \frac{d \zeta}{h^{2}(\zeta)}}{\int_{0}^{1} \frac{d \zeta}{h^{2}(\zeta)}}\right]
\end{aligned}
$$

where, $k_{r \ell}$ is the aqueous relative permeability. The terms in the brackets on the right-hand side of Equations (12) and (13) represent the ratio of mean flow channel radii for interconnected pores corresponding to the variably-saturated, frozen system to that for a water saturated system. The first term of the numerator represents all the pores with hydraulic radii smaller than the largest water filled pores, including those occupied by ice. The second term in the numerator is a correction to account for the pore space occupied by the occluded ice. Equations (12) and (13) are solved using the inverse form of the van Genuchten soil-moisture retention function, Equations (8) and (9), for the $h(\zeta)$ function yielding the following expressions

$$
\begin{aligned}
& k_{r \ell}=\left(\bar{s}_{\ell}\right)^{1 / 2}\left[1-\left(1-\left(\bar{s}_{\ell}\right)^{1 / m}\right)^{m}\right]^{2} \text { where } m=1-\frac{1}{n} \\
& k_{r \ell}=\left(\bar{s}_{\ell}\right)^{2}\left[1-\left(1-\left(\bar{s}_{\ell}\right)^{1 / m}\right)^{m}\right] \text { where } m=1-\frac{2}{n}
\end{aligned}
$$

Similarly, when the Equations (12) and (13) are solved using the inverse Brooks and Corey soil moisture retention function, Equations (10) and (11), the aqueous relative permeability functions appear as

$$
\begin{aligned}
& k_{r \ell}=\left(\bar{s}_{\ell}\right)^{(5 / 2+2 / \lambda)} \\
& k_{r \ell}=\left(\bar{s}_{\ell}\right)^{(3+2 / \lambda)}
\end{aligned}
$$

Aqueous relative permeabilities as a function of ice saturation for a totally saturated system (i.e., $s_{\ell}+s_{i}=1.0$ ) are shown graphically for Equations (14) through (17) in Figure 2. 


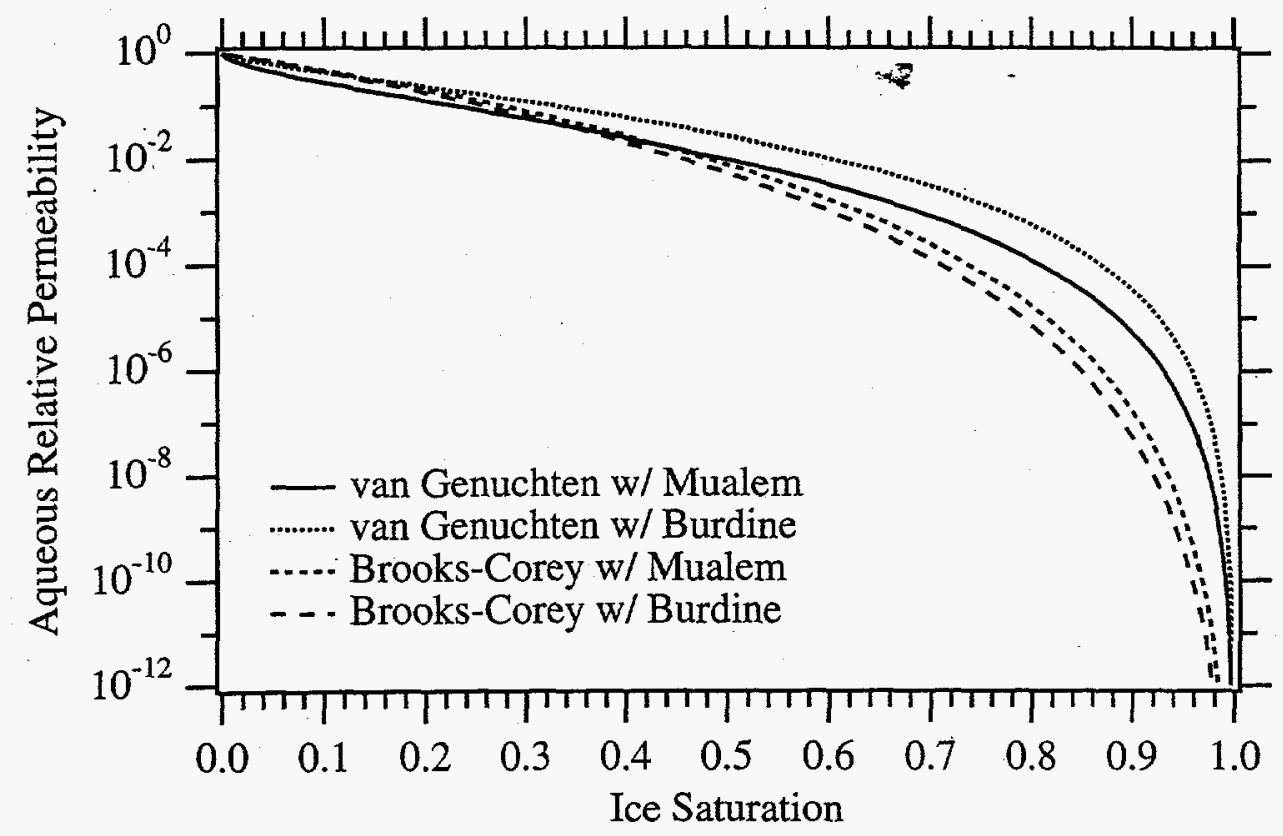

Figure 2. Aqueous Relative Permeability versus Ice Saturation

$$
m=0.5, \lambda=0.5, s_{\ell}+s_{i}=1.0, s_{m}=0.1
$$

\section{NUMERICAL SIMULATOR}

The described constitutive relations for computing phase saturations and relative permeabilities for freezing conditions were incorporated into the Two-Phase Nonisothermal operational mode of the STOMP simulator [White and Lenhard 1993]. The STOMP simulator is an integral-volume finite-difference based solver for multiple-phase flow and transport systems in subsurface environments. Governing equations that describe heat and fluid and transport in variably saturated geologic media are solved simultaneously with NewtonRaphson iteration to resolve the equation nonlinearities. Solute transport is solved sequentially from the coupled flow solution. The STOMP simulator utilizes a variable source code configuration, which allows the execution memory and speed to be tailored to the problem specifics. The governing equations for the Two-Phase Nonisothermal operational mode are those for conservation of water mass, air mass, solute măss, and thermal energy. Transport of mass and energy occurs over four distinct phases: aqueous, gas, ice, and solid. The aqueous phase primarily comprises liquid water, with small quantities of dissolved air; the gas phase comprises variable concentrations of air and water vapor; and the ice phase contains pure frozen water.

The water and air mass conservation equations equate the time rate of change in mass within a control volume with the flux of the mass crossing the control volume surfaces as

$$
\frac{\partial}{\partial t}\left[\sum_{p=\ell, g, i}\left(n_{D} \omega_{p}^{j} \rho_{p} s_{p}\right)\right]=\sum_{p=\ell, g}\left(\nabla\left[\frac{\omega_{p}^{j} \rho_{p} k_{r p} \mathbf{k}}{\mu_{p}}\left(\nabla P_{p}+\rho_{p} g \mathbf{z}\right)\right]\right)
$$




$$
+\sum_{p=\ell, g}\left(n_{D} \rho_{p} s_{p} \tau_{p} \frac{M^{j}}{M_{p}} \mathbf{D}_{p}^{j} \nabla \chi_{p}^{j}\right)+\dot{m}^{j} \text { for } j=\$, a
$$

where $t$ is time (s), $n_{D}$ is the diffusive porosity, $\omega$ is the mass fraction, $\mathbf{k}$ is the intrinsic permeability tensor $\left(\mathrm{m}^{2}\right), \mu$ is the dynamic viscosity ( $\mathrm{Pa} \mathrm{s}$ ), $\mathbf{z}$ is the gravitational vector, $\tau$ is the tortuosity, $M$ is the molecular weight $(\mathrm{kgmol} / \mathrm{kg}), \mathbf{D}$ is the diffusion-dispersion coefficient $\left(\mathrm{m}^{2} / \mathrm{s}\right), \chi$ is the mole fraction, $\dot{m}$ is the mass source rate $(\mathrm{kg} / \mathrm{s})$, the subscripts $\ell, g$, and $i$ indicate aqueous, gas, and ice phase, respectively, and the superscripts $w$ and $a$ indicate water and air mass, respectively. The conservation equation for thermal energy equates the time rate of change of thermal energy within the control volume with the heat flux crossing the control volume surfaces as

$$
\begin{aligned}
& \frac{\partial}{\partial t}\left[\sum_{p=\ell, g, i}\left(n_{D} \rho_{p} s_{p} u_{p}\right)+\left(1-n_{T}\right) \rho_{s} u_{s}+\left(n_{T}-n_{D}\right) \rho_{\ell} u_{\ell}\right]= \\
& -\sum_{p=\ell, g}\left(\nabla\left[\rho_{p} h_{p} \mathbf{V}_{p}\right]\right)+\nabla\left[\mathbf{k}_{e} \nabla T\right]+\sum_{j=w, a}\left(\dot{m}^{j} h^{j}\right)+\dot{q}
\end{aligned}
$$

where $u$ is internal energy $(\mathrm{J} / \mathrm{kg}), n_{T}$ is the total porosity, $h$ is the enthalpy $(\mathrm{J} / \mathrm{kg}), \mathbf{V}$ is the Darcy flow velocity $\left(\mathrm{m}^{3} / \mathrm{m}^{2} \mathrm{~s}\right), \mathbf{k}_{e}$ is the equivalent thermal conductivity $(W / \mathrm{m} \mathrm{K}), \dot{q}$ is the thermal energy source (W), and the subscript $s$ indicates the solid phase. Constitutive functions relate the primary unknowns of the governing equations to the secondary variables. Closure on the system of equations for the Two-Phase Nonisothermal operational mode requires three primary variables (unknowns). The STOMP simulator uses a primary variable switching scheme for phase transitions. For total water saturations less than one the primary unknowns are aqueous pressure, gas pressure, and temperature; and for total water saturations equal to one the primary unknowns are aqueous pressure, air partial pressure, and temperature.

\section{NUMERICAL APPLICATION}

The STOMP simulator with the constitutive relations for freezing conditions described above was applied to a problem similar to the laboratory experiments of Jame [1977]. These experiments involved imposing different temperature gradients across a radially insulated horizontal lucite tube $(0.3 \mathrm{~m}$ in length and $0.1 \mathrm{~m}$ in diameter) filled with partially saturated porous media. Both ends of the tube were sealed to prevent water flow across these boundaries. Gas pressures were maintained at atmospheric conditions. The porous medium was a silica flour (dry bulk density of $1.335 \mathrm{~g} / \mathrm{cm}^{3}$ ) of which $72 \%$ passed a \#325 sieve $(0.044 \mathrm{~mm})$. Initial conditions for the experiments were uniform temperatures and saturations along the tube length. Each experiment was initiated by lowering the temperature of the cool end below the freezing point and maintaining the temperature of the warm end at the initial temperature. During the course of the experiments, which each lasted $72 \mathrm{hr}$, constant temperature conditions were maintained at both ends of the tube. 
To numerically simulate these laboratory experiments, Jame and Norum [1980] used experimentally determined data to relate liquid ater content as a function of temperature for freezing conditions. For the present investigation, van Genuchten moisture retention function parameters were estimated from grain size distribution data reported by Jame [1977] for the silica flour according to the technique by Mishra et al. [1989]. The determined parameters were $\alpha=0.279 \mathrm{~m}^{-1}, n=1.64, n_{D}=0.496$, and $s_{m}=0.0$. These parameters were then used in Equations (3), (4), and (9), for totally saturated conditions, to compute the unfrozen water content as a function of temperature for freezing conditions. The resulting function and associated van Genuchten parameters are compared against the experimental data of Jame [1977] in Figure 3. The method of Mishra et al. was additionally used to estimate a saturated soil hydraulic conductivity of $3.07 \times 10^{-5} \mathrm{~m} / \mathrm{s}$, which compared well with the value of $3.45 \times 10^{-5} \mathrm{~m} / \mathrm{s}$, extracted from the diffusivity data reported by Jame [1977].

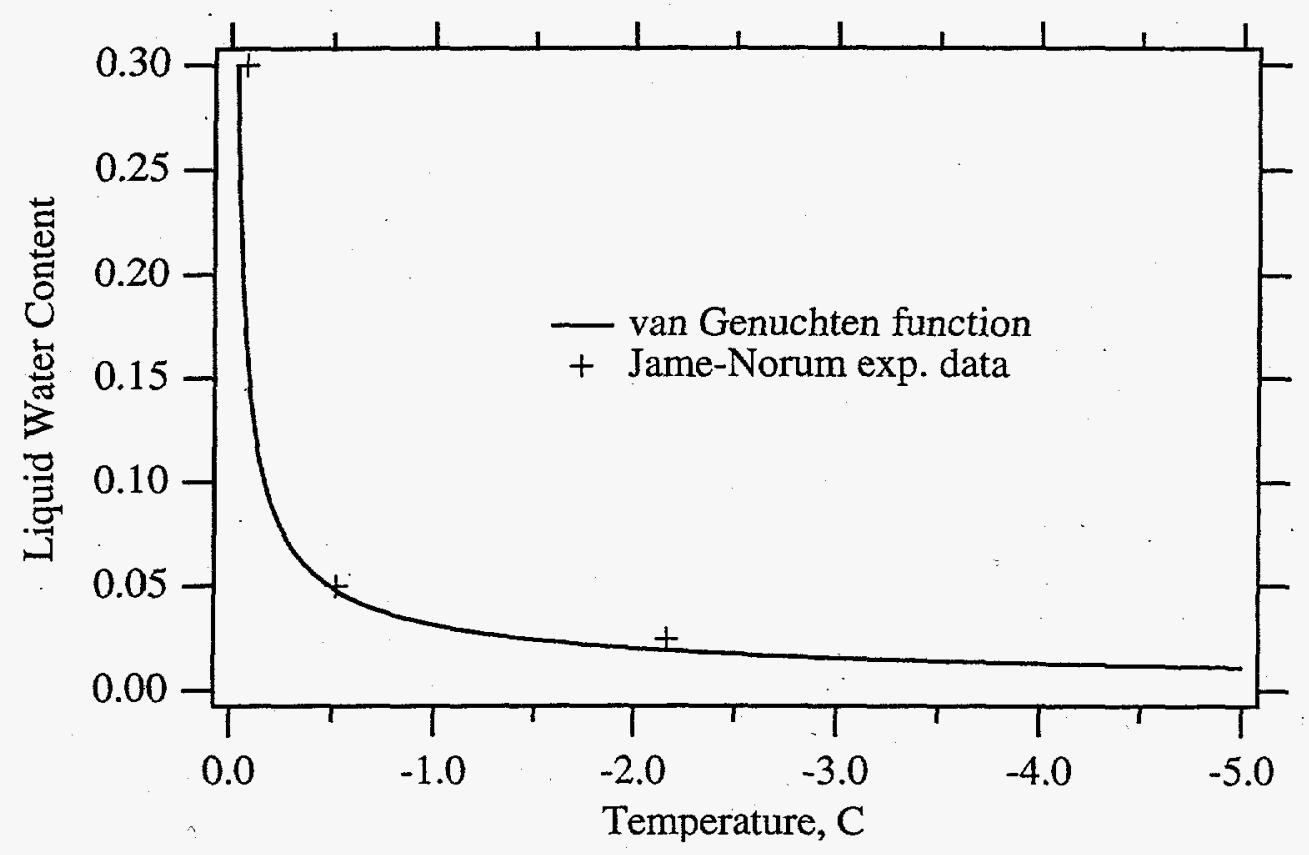

Figure 3. Unfrozen Water Content versus Temperature

$$
\alpha=0.279 \mathrm{~m}^{-1}, n=1.64, m=1-1 / n, \overline{\bar{s}}_{\ell}=1.0, s_{m}=0.0, n_{D}=0.496
$$

The effective thermal conductivity was computed following the method of de Vries [1963] from estimated physical properties of the soil matrix, aqueous phase, gas phase, and ice according to the expression

$$
k_{e}=\sum_{n=s, \ell, g, i} w_{n} n_{D} s_{n} k_{n} / \sum_{n=s, \ell, g, i} w_{n} n_{D} s_{n}
$$

where $w$ is the phase-component weighting factor and $k$ is the phasecomponent thermal conductivity $(\mathrm{W} / \mathrm{m} \mathrm{K})$. Weighting factors typically depend on the ratio of the average temperature gradient in the component to the average temperature gradient in the equivalent medium. For the present analysis weighting factors were set equal to 1.0. Soil particle thermal conductivity and 
specific heat values of $2.3 \mathrm{~W} / \mathrm{m} \mathrm{K}$ and $837.0 \mathrm{~J} / \mathrm{kg} \mathrm{K}$ were determined from the reported data [Jame and Norum 1980].

To demonstrate the application of the proposed capillary head scaling approach for computing saturations under variably saturated freezing conditions, two freezing-induced redistribution simulations were performed, which generally followed the experiments of Jame and Norum [1980]. In both simulations a horizontal tube of soil at uniform liquid water content (15.6\% dry weight) and temperature $(+20 \mathrm{C})$ was cooled on one end to $-10 \mathrm{C}$ and held at that temperature while the other end remained at $+20 \mathrm{C}$. Both simulations were executed over a 72-hr period using 233 nonuniform time steps. The first simulation used a saturated hydraulic conductivity of $256 \mathrm{~cm} /$ day; whereas, the second used a reduced value of $25.6 \mathrm{~cm} /$ day. Total moisture content (by \% dry weight) and temperature profiles are shown for the simulations with the higher hydraulic conductivity soil in Figures 4 and 5. Total moisture contents include the weights of both the frozen water and unfrozen liquid water. The results demonstrate the experimentally observed phenomena of freezing-induced redistribution of soil moisture. The zone of freezing acts as a strong sink for liquid water by effectively reducing the aqueous pressure, which induces liquid water to flow into the zone of freezing. Water vapor diffusion through the gas phase also occurs, but the quantities of redistributed water greatly exceed that which can be accounted for by water vapor diffusion. At each point in time, the freezing point isotherm $(0 \mathrm{C})$ occurs in distance between the two points that bracket the abrupt change in total moisture content.

Total moisture content and temperature profiles for the simulation with the soil of lower hydraulic conductivity are shown in Figures 6 and 7. These results differ markedly in the total moisture content profiles. The lower hydraulic conductivity of the soil inhibits the freezing-induced flow of liquid water to the freezing zone thus yielding lower total moisture contents near the cold end. Near the tube midpoint, however, the total moisture contents are greater than those for the higher permeability soil, thus producing a U-shaped profile. These U-shaped profiles have been observed experimentally [Dirksen and Miller 1966] and occur as the temperature profile approaches steady-state and the freezing front slows to a halt. As with the simulation results for higher permeability soil, the freezing point isotherm occurs within the sharp discontinuity in total moisture content.

\section{CONCLUSIONS}

A general formulation to predict phase saturations for variably saturated, freezing conditions as a function of phase pressure, temperature, and solute concentrations has been developed for nonheaving conditions. The approach relates the scaled air-water capillary head to the ratio of "free" aqueous saturation to the normalized "free" pore volume and the scaled ice-water capillary head to the unfrozen fraction of liquid water. This approach allows equilibrium saturations as a function of temperature, phase pressure, and solute concentration for different soils to be computed through conventional soilmoisture retention functions (e.g., van Genuchten and Brooks and Corey). Aqueous-phase relative permeability functions were derived for variably saturated, freezing conditions using inverse van Genuchten and Brooks and Corey moisture retention functions in conjunction with the Mualem and Burdine models for predicting the relative permeability from knowledge of the soilmoisture retention curve. The developed functions were demonstrated through 


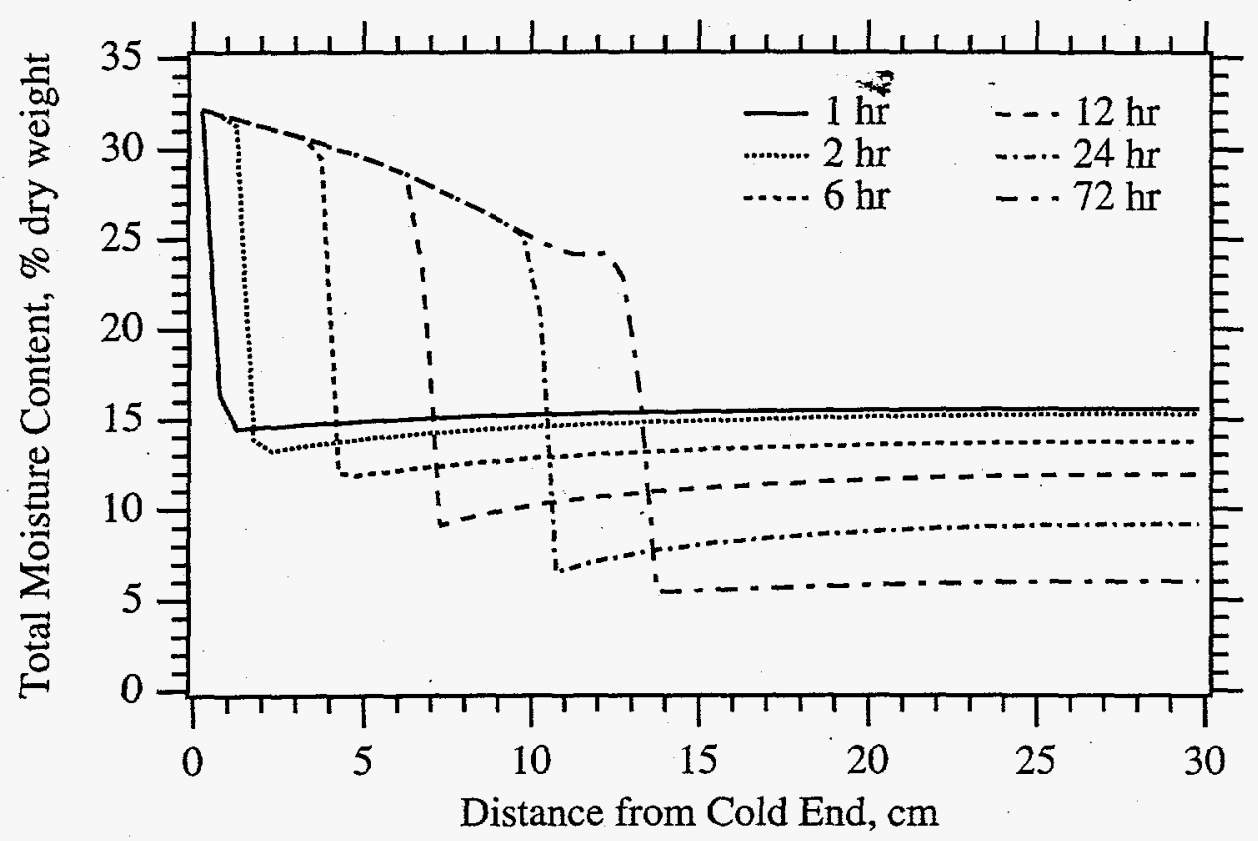

Figure 4. Total Moisture Content Profile for the Higher Permeability Soil

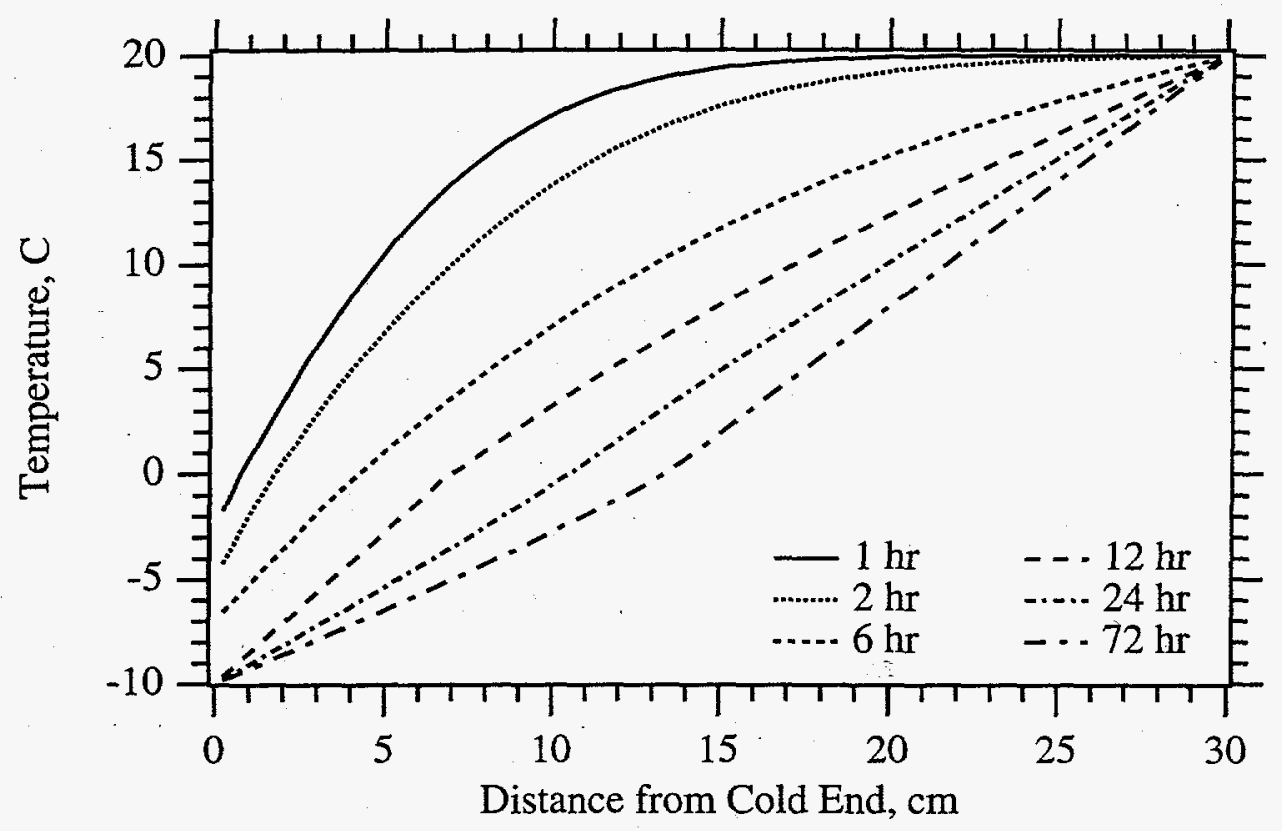

Figure 5. Temperature Profile for the Higher Permeability Soil 


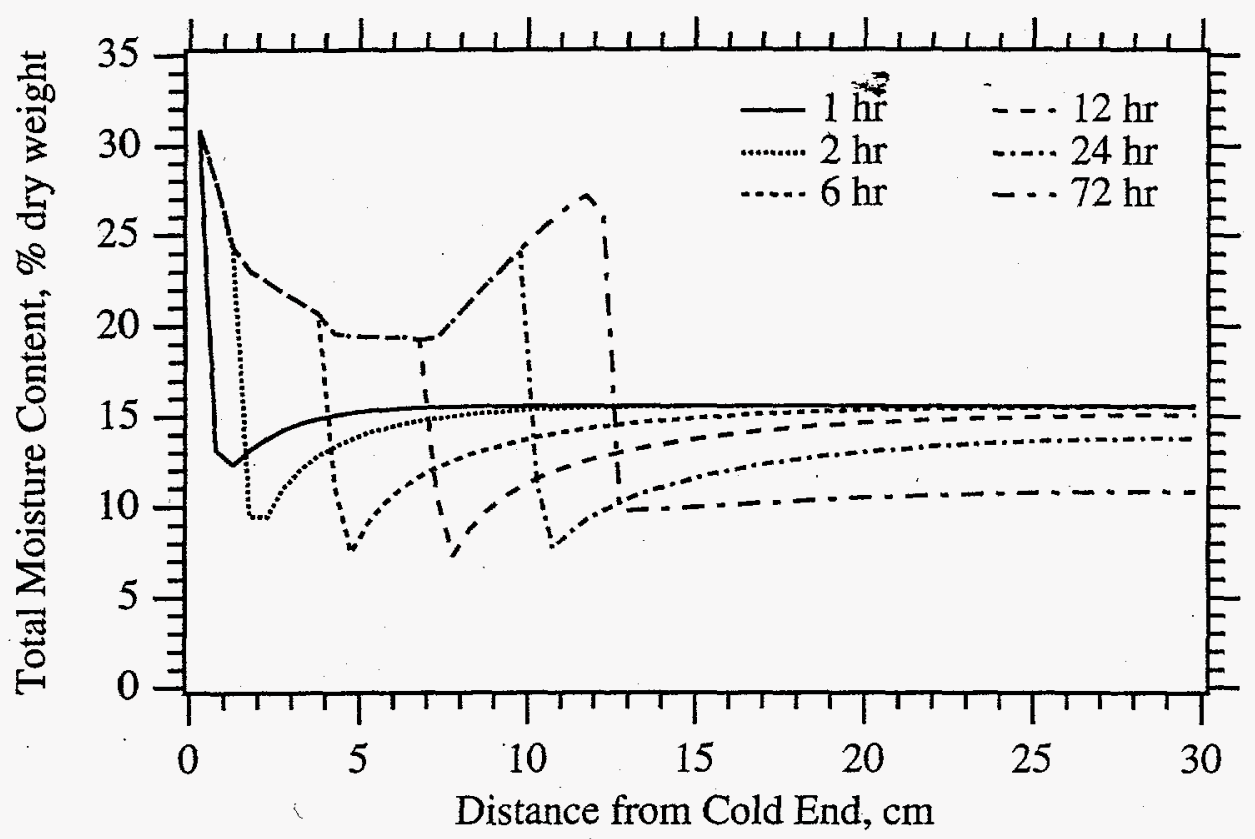

Figure 6. Total Moisture Content Profile for the Lower Permeability Soil

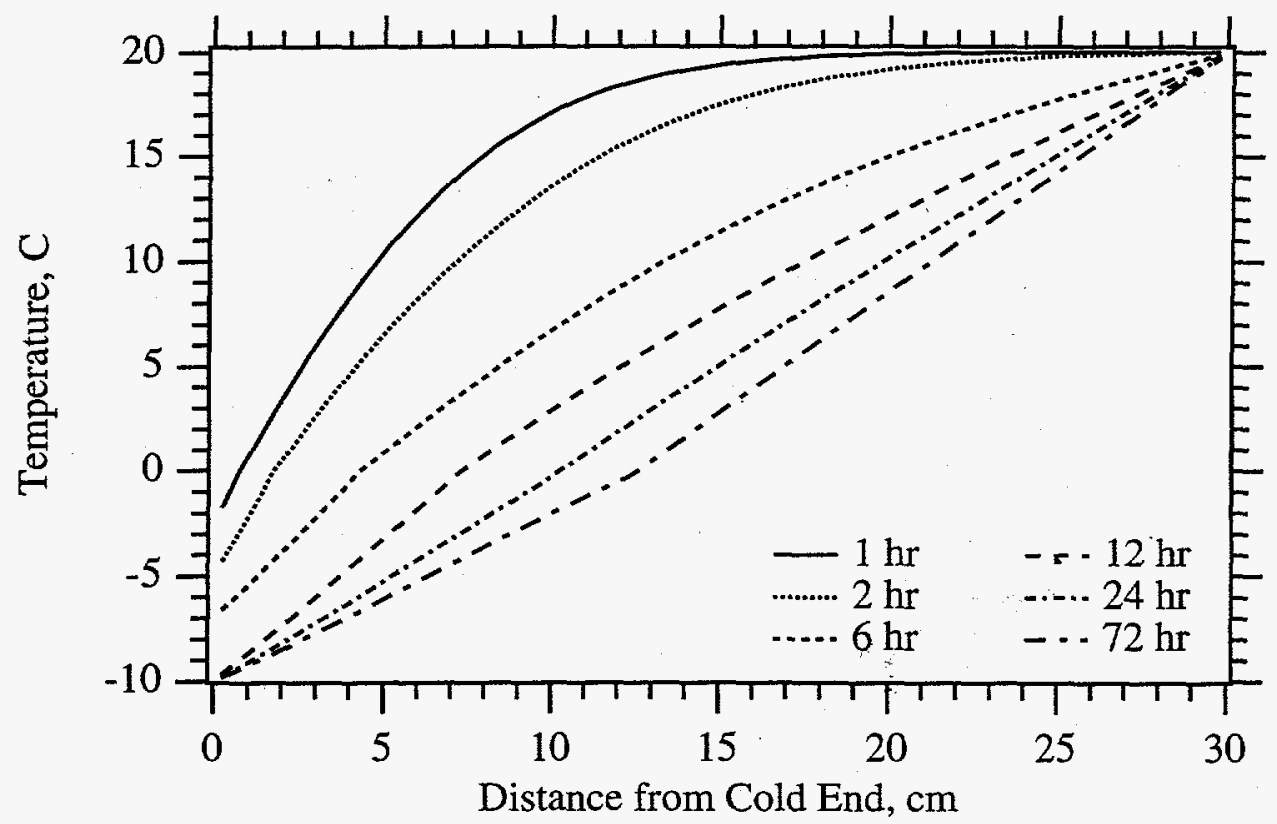

Figure 7. Temperature Profile for the Lower Permeability Soil 
the simulation of two freezing-induced moisture redistribution problems. The formulations were demonstrated to capture the essential features of moisture redistribution and ice formation observed experimentally. Comparisons of unfrozen water fractions with experimental measurements for silica flour show close agreement. Further studies will be required, however, to determine whether the freezing-induced capillary draw forces predicted by the proposed formulations agree with experimental measurements for a variety of soils. Given the appropriateness of the proposed functions, the numerical simulations revealed that affective cryogenic barrier formation will be dependent on soil thermal and moisture-soil retention properties in addition to cooling rates and freezing front migration rates.

\section{ACKNOWLEDGMENTS}

This work is funded by the Office of Technology Development, within the Department of Energy's Office of Environmental Management, under the Characterization, Monitoring, and Sensor Technology Integrated Program and the VOCs in Arid Soils Integrated Demonstration. Pacific Northwest Laboratory is operated by Battelle Memorial Institute for the U.S. Department of Energy under Contract DE-AC06-76RLO 1830.

\section{REFERENCES}

1. Brooks, R. H. and A. T. Corey. 1964. "Hydraulic Properties of Porous Media Affecting Fluid Flow." Hydrology Paper no. 3, Civil Engineering Dept., Colorado State Univ., Fort Collins, Colorado.

2. Burdine, N. T. 1953. "Relative Permeability Calculations from Pore Size Distribution Data." Petr. Trans., Am. Inst. Min. Metall. Pet. Eng., 198:71-77.

3. Cary, J. W. and H. F. Maryland. 1972. "Salt and Water Movement in Unsaturated Frozen Soil.” Soil Sci. Soc. Am. Proc., 36:549-555.

4. de Vries, D. A. 1963. "The Thermal Properties of Soil." Physics of Plant Environment, North-Holland Publishing Co., Amsterdam. pp. 210-235.

5. Dirksen, C. and R. D. Miller. 1966. "Closed-System Freezing of Unsaturated Soil.” Soil Sci. Soc. Am. Proc., 30:168-173.

6. Engelmark, H. and U. Svensson. 1993. "Numerical Modelling of Phase Change in Freezing and Thawing Unsaturated Soil." Nordic Hydrology, 24(2):95-110.

7. Fuchs, M., G. S. Campbell, and R. I. Papendick. 1978. "An Analysis of Sensible and Latent Heat Flow in a Partially Frozen Unsaturated Soil." Soil Sci. Soc. Am. J., 42(3):379-385.

8. Guymon, G. L. and J. N. Luthin. 1974. "A Coupled Heat and Moisture Transport Model for Arctic Soils." Water Resour. Res., 10(5):9151001. 
9. Harlan, R. L. 1973. "Analysis of Coupled Heat-Fluid Transport in Partially Frozen Soil." Water Resour. Res., 9(5):1314-1323.

10. Jame, Y. W. 1977. Heat and Mass Transfer in Freezing Unsaturated Soil. Ph.D. Dissertation, University of Saskatoon, Saskatoon.

11. Jame, Y. W. and D. I. Norum. 1980. "Heat and Mass Transfer in a Freezing Unsaturated Porous Medium." Water Resour. Res., 16(4):811819.

12. Kay, B. D. and E. Perfect. 1988. "Heat and Mass Transfer in Freezing Soils: Review of Current Understanding." In Proc. of the Fifth International Symp. on Ground Freezing, A. A. Balkema, Rotterdam.

13. Lenhard, R. J. 1994. "Scaling Fluid Content-Pressure Relations of Differentfluid Systems in Porous Media." In Proc. of the Fourteenth Annual American Geophysical Union Hydrology Days, Hydrology Days Publications, Atherton, California. pp. 223-235.

14. Leverett, M. S. and W. B. Lewis. 1941. "Steady Flow of Gas-OilWater Mixtures through Unconsolidated Sands." Trans. AIME, Am. Inst. Min. Metall. Pet. Eng., 142:152-169.

15. Loch, J. P. G. 1977. "Thermodynamic Equilibrium Between Ice and Water in Porous Media." Soil Sci., 126:77-80.

16. Miller, R. D. 1980. "Freezing Phenomena in Soils." Chapter 11 in Applications in Soil Physics, eds. D. Hillel, pp. 254-299. Academic Press, New York.

17. Mishra, S., J. C. Parker, and N. Singhal. 1989. "Estimation of Soil Hydraulic Properties and Their Uncertainty from Particle Size Distribution Data." J. Hydrol., 108:1-18.

18. Mualem, Y. 1976. "A New Model for Predicting the Hydraulic Conductivity of Unsaturated Porous Media." Water Resour. Res., 12:513-522.

19. Panday, S. and M. Y. Corapcioglu. 1994. "Theory of Phase-Separate Multicomponent Contaminant Transport in Frozen Soils." J. Contam. Hyd., 16:235-269.

20. Parker, J. C. and R. J. Lenhard. 1987. "A Model for Hysteretic Constitutive Relations Governing Multiphase Flow 1. Saturation-Pressure Relations." Water Resour. Res., 23(12):2187-2196.

21. van Genuchten, M. Th. 1980. "A Closed-Form Equation for Predicting the Hydraulic Conductivity of Unsaturated Soils." Soil Sci. Soc. Am. J., 44:892-898.

22. White, M. D. and R. J. Lenhard. 1993. "Numerical Analysis of a ThreePhase System with a Fluctuating Water Table." In Proc. of the Fourteenth Annual American Geophysical Union Hydrology Days, Hydrology Days Publications, Atherton, California. pp. 219-236. 